\title{
Nonirritant and Cytocompatible Tinospora cordifolia Nanoparticles for Topical Antioxidant Treatments
}

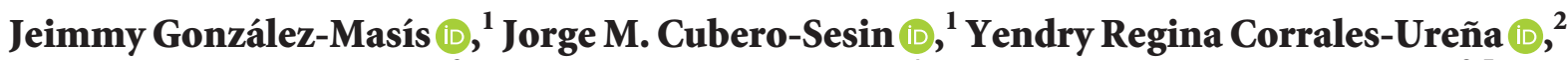 \\ Sara González-Camacho, ${ }^{3}$ Nohelia Mora-Ugalde $\mathbb{D}^{\mathrm{D}},{ }^{4}$ José Roberto Vega-Baudrit $\mathbb{D}^{2},{ }^{2,5}$ \\ Klaus Rischka, ${ }^{6}$ Virendra Verma, ${ }^{7}$ and Rodolfo J. Gonzalez-Paz $\mathbb{D}^{2}$ \\ ${ }^{1}$ Centro de Investigación y Extensión en Materiales, Escuela de Ciencia e Ingeniería de Los Materiales, \\ Instituto Tecnológico de Costa Rica, Cartago 159-7050, Costa Rica \\ ${ }^{2}$ National Laboratory of Nanotechnology LANOTEC, National Center of High Technology (CeNAT-CONARE), Pavas 1174-1200, \\ San José, Costa Rica \\ ${ }^{3}$ Biological Assay Laboratory (LEBi), Universidad de Costa Rica, San José 11501-2060, Costa Rica \\ ${ }^{4}$ National Center for Biotechnological Innovations (CENIBiot), National Center of High Technology (-CeNAT-CONARE), \\ Pavas 1174-1200, San José, Costa Rica \\ ${ }^{5}$ Laboratorio de Polímeros (POLIUNA), Universidad Nacional, Heredia 86-3000, Costa Rica \\ ${ }^{6}$ Fraunhofer Institute for Manufacturing Technology and Advanced Materials, Adhesive Bonding Technology and Surfaces, \\ Wiener Straße 12, 28359, Bremen, Germany \\ ${ }^{7}$ Ayurvedic Physician Private Clinic \& Panchakarma Centre, Varanasi, India
}

Correspondence should be addressed to Rodolfo J. Gonzalez-Paz; drpazsowarigpa@gmail.com

Received 8 April 2020; Revised 21 June 2020; Accepted 9 July 2020; Published 21 August 2020

Academic Editor: Wen-Cheng Chen

Copyright (C) 2020 Jeimmy González-Masís et al. This is an open access article distributed under the Creative Commons Attribution License, which permits unrestricted use, distribution, and reproduction in any medium, provided the original work is properly cited.

\begin{abstract}
Tinospora cordifolia extract contains antioxidants such as polyphenols, and thus, it has been used as a natural phytochemical antioxidant therapeutic agent. Many of these compounds are insoluble or only partially soluble in water. In this study, we produced a novel aqueous nanoparticle formulation, with an average particle size of $182.9 \pm 3.8 \mathrm{~nm}$, to improve the dispersion of the bioactive compounds in water and to increment its bioavailability. The nanoparticles are composed of polyphenols, alkaloids, and glycosides. We studied the effect of this nanoparticle formulation on mouse 3T3 fibroblast cell viability and New Zealand rabbit dermal irritability tests. Concentrations of $2.5,25$, and $250 \mu \mathrm{g} / \mathrm{mL}$ resulted in similar cell viability to cells in culture media. An intermediate concentration of $12.45 \mathrm{mg} / \mathrm{ml}$ was used for the acute dermal irritability test. There were no severe alterations that compromised animal health. These results represent a precedent for application of such nanoparticles derived from plant stems, such as Tinospora cordifolia, in biomedicine and in antiaging cosmetic treatments.
\end{abstract}

\section{Introduction}

Tinospora cordifolia, also known as Guduchi, is a deciduous climbing shrub, found in India, especially in tropical areas, being famous for its numerous properties and uses in the ancient Ayurveda and Tibetan medicinal system [1]. Tinospora cordifolia is found ascending to an altitude of 1000 feet in Southeast Asian countries such as Indonesia, the Philippines, Thailand, Myanmar, China, and Sri Lanka [2]. It is used to prepare tonics, vitalizers, antiallergics, and treatments for diabetes mellitus, among others $[3,4]$. The beneficial properties of this plant are associated with a large number of chemical components, such as alkaloids, diterpenoid lactones, glycosides, steroids, sesquiterpenoids, phenolic compounds, and aliphatic compounds that present immunomodulatory activities [5]. These compounds exist in plant stem, leaves, roots, and fruits [4]. Several studies have reported that Tinospora cordifolia ethanolic extract (TEC) exhibits higher antioxidant activity, 
using in vitro antioxidant activity screening models such as nitric oxide and superoxide radical scavenging activity, inhibition of lipid peroxidation, and reduction of ferric ions [6]. This antioxidant properties are attributed to the strong free radical scavenging properties against superoxide anion $\left(\mathrm{O}^{2-}\right)$ and hydroxyl radicals $(\mathrm{OH})$, through a series of coupled reactions with the help of enzymes $[7,8]$. In regards to toxicity and side effects, the Ayurvedic literature reports that Tinospora can cause constipation, if it is taken regularly at high doses. However, it has been reported that no side effects or adverse reactions have been observed when the stem extract of Tinospora was administered in rabbits up to an oral dose as high as $1.6 \mathrm{~g} / \mathrm{kg}$ and to rats up to a dose of $1 \mathrm{~g} / \mathrm{kg}$ of total plant extract. Little is known about the toxicology of this product in humans [9]. The presence of compounds such as 2,4-bis(1,1-dimethylethyl)-phenol and palmitic acid could provide the antioxidant properties [10]. Many of these compounds are partially soluble in water, and this limits its use in aqueous formulations. The usual preparation protocol is to cut part of the plant into small pieces, let to dry (usually in the shade), and grind these pieces to produce a powder, which can be dispersed in water-ethanol or methanol mixtures $[1,3,9]$. To improve the solubility in water and increase the bioavailability of the bioactive compounds, we will produce a nanosuspension of TEC in water applying sonication and filtration to decrease the aggregate sizes of insoluble compounds. Characterization techniques such as using Fourier-transform infrared spectroscopy (FTIR), gas chromatography-mass spectrometry (GC-MS), and ${ }^{13} \mathrm{C}$ - and ${ }^{1} \mathrm{H}-\mathrm{NMR}$ (nuclear resonance spectroscopy) were used. The nanoparticle suspensions will be characterized using dynamic light scattering (DLS) and atomic force microscopy (AFM) to determine their particle size and morphology. The effect of the Tinospora cordifolia nanoparticle suspension on 3T3 fibroblast viability and animal dermal irritability was also evaluated.

\section{Experimental}

2.1. Production of Nanoparticle Aqueous Formulation. Dried Tinospora cordifolia stems from Varanasi (latitude: $25^{\circ} 19^{\prime} 3.52^{\prime \prime} \mathrm{N}$ and longitude: $82^{\circ} 58^{\prime} 26.09$ ), India, were pulverized using an industrial blender and mixed with $250 \mathrm{~mL}$ of ethanol. The alcoholic solution, with a concentration of $104.7 \mathrm{mg} / \mathrm{mL}$, was filtered and placed in an oven at $45^{\circ} \mathrm{C}$ for $16 \mathrm{~h}$ to obtain a dry extract. A $13.2 \mathrm{mg} / \mathrm{mL}$ aqueous suspension was prepared in ultrapurified water and sonicated to obtain the nanoparticulate solution. The conditions of the ultrasonic treatment were $4 \mathrm{~W}$ and $40 \%$ amplitude for $5 \mathrm{~min}$, using a probe of $6 \mathrm{~mm}$ diameter. The solution was filtered with a sterile filter of $0.2 \mu \mathrm{m}$ (Sartorius, Germany) and diluted to $2.5 \mu \mathrm{g} / \mathrm{mL}, 25 \mu \mathrm{g} / \mathrm{mL}$, and $250 \mu \mathrm{g} / \mathrm{mL}$ concentrations using ultrapure water.

\subsection{Characterization of the Tinospora cordifolia Extract and Nanoparticle Suspension}

2.2.1. Fourier-Transform Infrared Spectroscopy (FTIR). A Nicolet 6700 spectrophotometer was used, encompassing 4000 to $400 \mathrm{~cm}^{-1}$ wavenumber with a standard resolution of $0.09 \mathrm{~cm}^{-1}$ and a scanning speed of 32 spectrums $/ \mathrm{s}$.
2.2.2. Matrix-Assisted Laser Desorption/Ionization Time-ofFlight Mass Spectrometry (MALDI-ToF MS). Spectra were recorded on a Bruker Autoflex Speed (Bruker Daltonics, Bremen, Germany) mass spectrometer. The applied matrix was 2,5-dihydroxybenzoic acid (DHB, Sigma Aldrich, Germany) in methanol. The sample was dissolved in methanol. The matrix and sample were mixed in the ratio $10: 1$ (matrix : sample) and applied on a stainless steel target plate. The mixture was dried in the open air (dried droplet). A calibration was applied by using PEG 400 . The spectrum was recorded in the positive reflection mode by the accumulation of $5 \times 1000$ scans.

\subsubsection{Nuclear Magnetic Resonance Spectroscopy (NMR).} NMR spectra were recorded in $\mathrm{CDCl}_{3}$ as solvent, with a Bruker Advance DRX-600 spectrometer equipped with a Prodigy BBIO cryoprobe $\left({ }^{1} \mathrm{H}\right.$ at $600.22 \mathrm{MHz} ;{ }^{13} \mathrm{C}$ at $150.94 \mathrm{MHz}) .{ }^{1} \mathrm{H}$ shifts were calibrated by using the chemical shifts of the $\mathrm{CDCl}_{3}$ solvent signal $(\delta \mathrm{H}=7.26 \mathrm{ppm}, 300 \mathrm{~K})$ as an internal standard $[11] .{ }^{13} \mathrm{C}$ chemical shifts were calibrated using the IUPAC recommendations applying the conversion factor of 0.25144953 for the calculation of the absolute frequency of ${ }^{13} \mathrm{C}(\delta=0.0 \mathrm{ppm})[12]$.

2.2.4. Total Polyphenol Content. Solutions with a concentration of $100,50,10,5$, and $1 \mu \mathrm{g} / \mathrm{mL}$ were prepared for the determination of the calibration curve. $0.75 \mathrm{~mL}$ of distilled water, $0.5 \mathrm{~mL}$ of the solutions, and $0.625 \mathrm{~mL}$ of the Folin reagent $(1 \mathrm{~N})$ were placed in a volumetric flask of $5 \mathrm{~mL}$. Then, the flask was filled with a solution of $\mathrm{Na}_{2} \mathrm{CO}_{3} \cdot 10 \mathrm{H}_{2} \mathrm{O}(20 \% \mathrm{~m} / \mathrm{v})$. The mixtures were incubated for $40 \mathrm{~min}$ at room temperature in the dark. After the reaction period, the absorbance of the solutions was measured at a wavelength of $725 \mathrm{~nm}$ in a Shimadzu UV-Vis spectrophotometer (model UV-1800, Shimadzu Corporation, Kyoto, Japan).

2.2.5. Dynamic Light Scattering (DLS). The average nanoparticle hydrodynamic diameter was measured using a Malvern Zetasizer instrument at $25^{\circ} \mathrm{C}$.

2.2.6. Atomic Force Microscopy (AFM). The $20 \mu \mathrm{L}$ nanoparticle solution was placed on a freshly cleaved mica substrate and dried at room environmental conditions overnight. The sample topography was analyzed in air using an atomic force microscope (Asylum Research, Santa Barbara, CA), operated in the tapping mode. Silicon probes (model Tap150Al-G), backside with a resonance frequency of $150 \mathrm{kHz}$ and a force constant of $5 \mathrm{~N} / \mathrm{m}$, were used.

2.2.7. Cell Culture. Mouse 3T3 fibroblast cell line (ATCC, USA) was incubated (Binder, Germany) and cultured in standard conditions $\left(37^{\circ} \mathrm{C}, 5 \% \mathrm{CO}_{2}\right)$ in Dulbecco's modified Eagle's medium (DMEM, Gibco ${ }^{\circledR}$ ). The medium was supplemented with $10 \% \mathrm{v} / \mathrm{v}$ fetal bovine serum (FBS) (SigmaAldrich) and changed every other day. The cells were 
subcultured using routine trypsin/EDTA (Merck) procedures.

2.2.8. Viability Assay. Exponentially growing 3T3 cells were seeded in a 96-well plate at a density of 700 cells $/ 100 \mu \mathrm{L} /$ well and left in the incubator growing for $24 \mathrm{~h}$. Afterwards, $50 \mu \mathrm{l}$ of the Tinospora cordifolia nanoparticle suspensions of 2.5, 25 , and $250 \mu \mathrm{g} / \mathrm{mL}$, containing resazurin salts (SigmaAldrich), was added to the culture with or without cells. Fluorescence readings were carried out using a microplate reader (Synergy H1 Hybrid, Biotek) with a gain of 70 at 0, 24, 48 , and $72 \mathrm{~h}$, and excitation and emission wavelengths of 540 and $590 \mathrm{~nm}$, respectively. The fluorescence blank was subtracted from the average of the data (supernatant with the culture medium in the absence of the cells), and the percentage of viability was calculated using the following equation:

$$
\text { viability }(\%)=\frac{\text { average number of cells with treatment }}{\text { average number of cells without treatment }} \times 100 \text {. }
$$

2.2.9. Acute Dermal Irritability Test. The test evaluated the irritability of the aqueous solution of Tinospora cordifolia nanoparticle suspension at a concentration of $12.45 \mathrm{mg} / \mathrm{mL}$ and $\mathrm{pH}$ of 7 , on the healthy skin of a New Zealand rabbit.

(a) Administration of the substance to be tested: at least $24 \mathrm{~h}$ before the test, the hair of the animals was carefully cut on both sides of the back, in an approximate area of $6 \mathrm{~cm}^{2}$. Only animals whose skin was intact were used. A single dose of $0.5 \mathrm{~mL}$ of the undiluted test substance was applied with a 4-hour exposure, after which the residual material was removed using distilled water, so as not to disturb the integrity of the epidermis.

(b) Observation: inspections of the skin (erythema and edema) of the live animals were conducted at $24 \mathrm{~h}$, $48 \mathrm{~h}$, and $72 \mathrm{~h}$ after the administration of the test substance. Daily observation of the animals was conducted for 14 days after the application to determine the health status and subsequent responses or recovery. Weekends were omitted once it was demonstrated that after 72 hours of application, any signs of irritation or corrosion had disappeared.

(c) Irritation evaluation method: the records of dermal irritation were evaluated in conjunction with the nature and reversibility of the observed response. The severity scores were assigned through the use of the Primary Skin Irritation Scale. The individual scores did not constitute an absolute norm for the irritating properties of a material. They were considered as reference values and were supported by a complete description and evaluation of the observations.

(d) Classification of the substance to be tested: at the end of the observation period, the substance was classified according to the parameters given by the Globally Harmonized System of Classification and Labeling of Chemicals (GHS) and the Organization for Economic Cooperation and Development (OECD), as shown in Tables 1 and 2. The parameters to evaluate the animal health and the scale are shown in Tables 3 and 4, and the scale for evaluation of erythema and edema reactions is shown in Table 5 .

\section{Results and Discussion}

The chemical structure of the natural extract (TEC) and the nanoparticle suspensions (TEC-NPs) was analyzed using FTIR, as shown in Figure 1(a). The TEC spectrum shows a peak at $3380 \mathrm{~cm}^{-1}$ and $1080 \mathrm{~cm}^{-1}$ from the hydroxyl group, corresponding to free alcohols and/or water. The peak at $3395 \mathrm{~cm}^{-1}$ could be associated with phenolic compounds $[9,13]$. The presence of hydroxyl groups could be associated with compounds such as polyphenols, fatty acids, and monosaccharides $[13,14]$. The peak at $1730 \mathrm{~cm}^{-1}$ is associated with the stretching vibration of the $\mathrm{C}=\mathrm{O}$ steroids $[9,14,15]$. The peak at $1630 \mathrm{~cm}^{-1}$ corresponds to the $\mathrm{C}=\mathrm{C}$ bond of olefin. Peaks at $1180 \mathrm{~cm}^{-1}$ and $950 \mathrm{~cm}^{-1}$, both present in the nanoparticles and the extract, could be associated with the stretching vibrations of the $\mathrm{C}=\mathrm{O}$ and $\mathrm{C}-\mathrm{O}$ C groups, respectively [15]. Also, near $720 \mathrm{~cm}^{-1}$, a strong band appears, typical of the $\mathrm{C}-\mathrm{H}$ groups $[1,16]$. Comparison of the bands of the extract and the nanoparticles reveals peak shifts at higher wavenumbers, as well as an increase in the intensity of the absorption bands. This result suggests that some compounds could be less soluble in water than in ethanol, and their aggregates were removed during filtration. Also, the difference in chemical environment that influences the hydrogen bond formation and electrostatic interactions produce shifts on the absorption bands [17].

Figure 1(b) shows the peaks at $\mathrm{m} / z=393.122$ and $\mathrm{m} /$ $z=419.207$, indicated by red dots, which are associated with compounds contained in the extract such as secondary metabolites and polyphenol oligomers [18-20]. The compound at $m / z=419.207$ corresponds to sodium adduct of tinocordiside, a tricyclic sesquiterpenoid glycoside [21]. A $2 \mathrm{D}$ model of the structure is shown in Figure 2.

Tinocordiside is a glycoside well known for its traditional uses in treatment of neurological disorders such as ALS, Parkinson's disease, dementia, motor and cognitive deficits, and neuron loss in the spine and hypothalamus [23]. Immunomodulatory activity is also attributed to this compound [24] and for thrombolytic drugs [25]. The blue dots correspond to the DHB signal at $m / z=136.994,154.004,155.012,177.004$, 273.030, 300.150, and 361.976. The yellow dot at $\mathrm{m} / z=279.086$ corresponds to triphenylphoshinoxide $+\mathrm{H}^{+}$that is correlated to contamination from the packaging container where the extract was stored.

The ${ }^{13} \mathrm{C}-\mathrm{NMR}$ spectral data in Figure 3(a) show $\mathrm{C}$ aromatic atoms at 121.3, 124.3, 127.8, 129.5, 130.16, 131.67, $133.8,136.7$, and $136.8 \mathrm{ppm}$, which correspond to C-H shifts from aromatic rings and are the fingerprint of alkaloids such as $\mathrm{N}$-formylannonaine [26]. The $\mathrm{C}$ polyphenol fingerprint is $140.1,142$, and $145 \mathrm{ppm}$ [27]. 
TABLE 1: Substance classification tested according to GHS/OECD parameters.

\begin{tabular}{lccc}
\hline Corrosive (category 1) & Corrosive potential subclassification & \multicolumn{2}{c}{ Corrosive in 1 or more animals } \\
& & Exposition & Observation \\
\hline Corrosive & Corrosive subcategory 1A & $\leq 3$ minutes & $\leq 1$ hour \\
& Corrosive subcategory 1B & $\leq 3$ minutes to $\leq 1$ hour & $\leq 14$ days \\
& Corrosive subcategory 1C & $>1$ hour to $\leq 4$ hours & $\leq 14$ days \\
\hline
\end{tabular}

TABLE 2: Substance classification criterion tested according to GHS/OECD parameters.

\begin{tabular}{ll}
\hline Classification & Criterion \\
\hline & $\begin{array}{l}\text { (1) Average of } \geq 2.3 \leq 4.0 \text { for erythema/eschar or for edema in at least } 2 \text { of the } 3 \text { animals tested at } 24 \text { hours, } 48 \\
\text { hours, and } 72 \text { hours after removing the patch, or if the reactions are delayed, for classifications in } 3 \text { consecutive } \\
\text { days after the appearance of skin reactions, or }\end{array}$ \\
Irritative (Category 2) & $\begin{array}{r}\text { (2) inflammation that persists at the end of the observation period, normally } 14 \text { days and in at least } 2 \text { animals, } \\
\text { particularly taking into account alopecia (defined area) hyperkeratosis, hyperplasia, and flaking, or } \\
\text { (3) in some cases when there is a pronounced response variability between the animals, with well-defined } \\
\text { positive effects related to the exposure chemical in an animal but less than the previous criteria }\end{array}$ \\
\hline $\begin{array}{l}\text { Medium irritant } \\
\text { Category 3) }\end{array}$ & $\begin{array}{c}\text { Average of } \geq 1.5<2.3 \text { for erythema/eschar or for edema in at least } 2 \text { of the } 3 \text { animals tested at } 24 \text { hours, } 48 \\
\text { hours, and } 72 \text { hours or, if the reactions are delayed, for ratings on } 3 \text { consecutive days after the onset of skin } \\
\text { reactions (when they are not included in the previous category of irritation) }\end{array}$ \\
\hline Not irritating & When the criteria of Categories 1-3 are not met
\end{tabular}

TABle 3: Parameters of animal health evaluation.

\begin{tabular}{lc}
\hline Parameter & Description \\
\hline Hair appearance & Texture, color, fall \\
Skin appearance & Redness, dryness, exudation \\
Eyes and mucous membranes & Redness, dryness, abnormal secretion \\
Ataxia & Loss of balance, erratic walk \\
Paralysis & Loss of response in any limb \\
Reaction to stimuli & Response to touch or noise \\
Peripheral vasoconstriction & Pallor \\
Peripheral vasodilation & Redness \\
Piloerection & Stiff hair \\
Salivation & Excess of buccal secretion \\
Motor activity & Spontaneous abnormal muscle contraction, contraction or uncontrolled muscular stretching \\
Tremors and convulsions & Increase or decrease in respiratory rate \\
Breathing & Robin's test: pinching the skin, without returning to its normal position \\
Dehydration & Soft stools or watery stool \\
Diarrhea & Weight lose \\
Lose & Increase or decrease in normal activity, reflect or not
\end{tabular}

TABLE 4: Scale of values for animal health assessment parameters.

\begin{tabular}{lc}
\hline Grade & Description \\
\hline 0 & There is no alteration \\
1 & Mild alteration that does not affect the other parameters \\
2 & Moderate alteration that does not affect the general behavior of the animal \\
3 & Severe alteration that affects the general behavior of the animal \\
\hline
\end{tabular}

TABLE 5: Evaluation scale of dermal reactions (erythema and edema).

\begin{tabular}{|c|c|c|c|}
\hline Erythema formation & Value & Edema formation & Value \\
\hline No presence of erythema & 0 & No edema formation & 0 \\
\hline Very slight erythema (almost imperceptible) & 1 & Very slight edema (almost imperceptible) & 1 \\
\hline Well-defined erythema & 2 & Light edema (well-defined area with significant elevation) & 2 \\
\hline Moderate-to-severe erythema & 3 & Moderate edema (elevation of approximately $1 \mathrm{~mm}$ ) & 3 \\
\hline $\begin{array}{l}\text { Severe erythema (red beet) with formation of scabs } \\
\text { (deep lesions) }\end{array}$ & 4 & $\begin{array}{c}\text { Severe edema (elevation greater than } 1 \mathrm{~mm} \text { and extending beyond } \\
\text { the exposure area) }\end{array}$ & 4 \\
\hline Maximum possible & 4 & Maximum possible & 4 \\
\hline
\end{tabular}




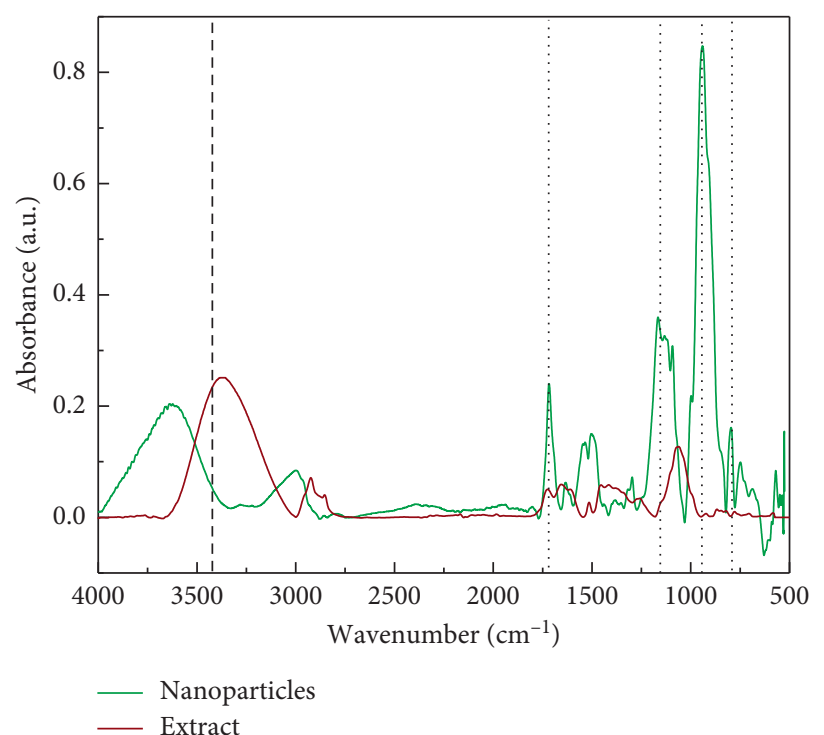

(a)

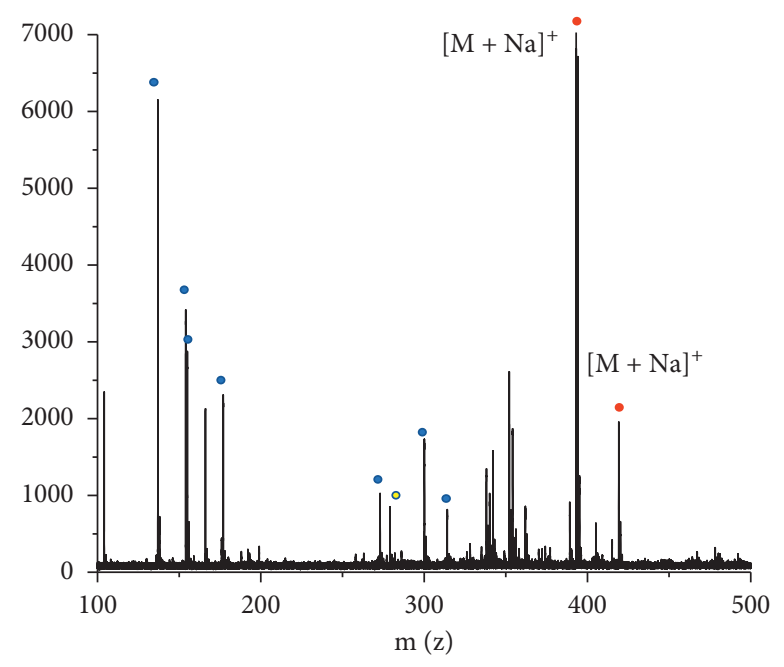

(b)

Figure 1: (a) FTIR spectra of the TEC extract and TEC-NP aqueous suspension. (b) MALDI-TOF spectrum in the range of 100 to 500 Da of the TEC-NP dried suspension.

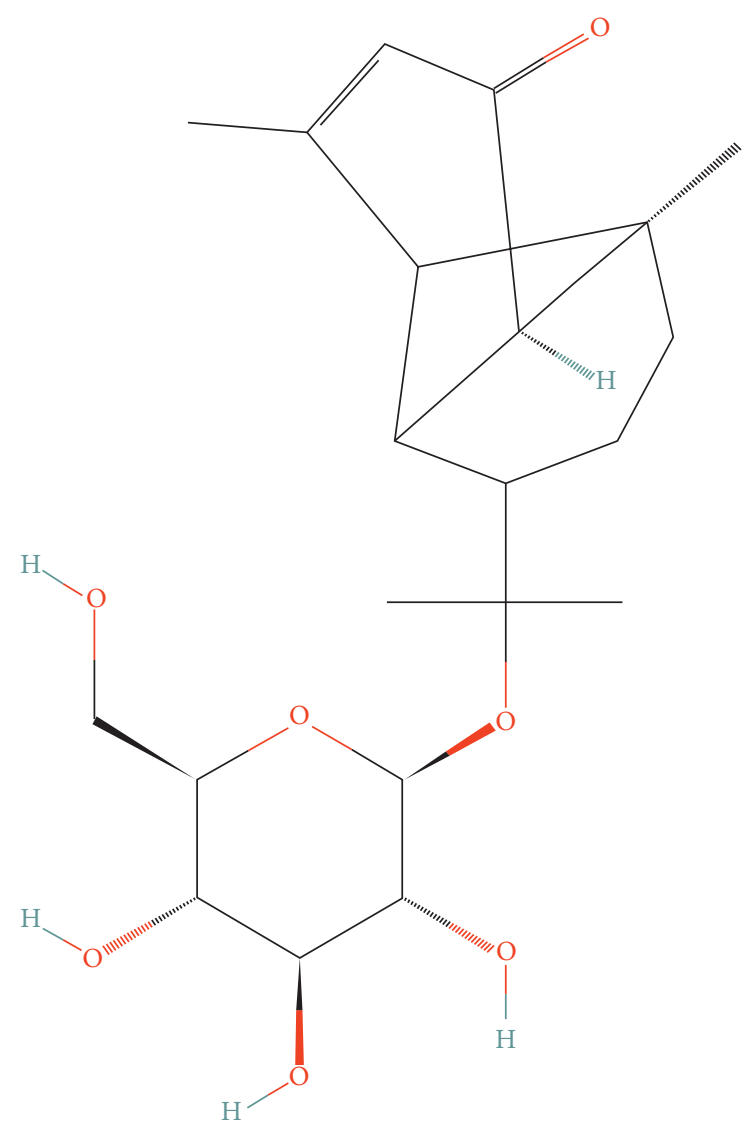

Figure 2: Tinocordiside compound 2D chemical structure [22].

The ${ }^{1} \mathrm{H}$-NMR spectral data in Figure 3(b) show protons at $1.97 \mathrm{ppm}$ assigned to $\mathrm{CH}_{2}$ groups, polysaccharides, or aromatic $\mathrm{OH}$ groups from polyphenols at $4.91 \mathrm{ppm}$, and the alkaloid fingerprint between 8 and $9 \mathrm{ppm} \mathrm{[28]}$. Carbon ${ }^{13} \mathrm{C}-$
NMR and ${ }^{1} \mathrm{H}-\mathrm{NMR}$ results confirm that preferential presence of polyphenols. The phenols in the extract were quantified using the Folin-Ciocalteu test. The results are shown in Table 6. The Folin-Ciocalteu reagent is sensitive to the reduction of hydroxyl groups of reducing sugars, and the values should be only taken as an approximation.

The nanoparticle formation was confirmed using AFM. Figure 4(a) shows aggregates contained in the filtered ethanolic TEC extract with a height above $100 \mathrm{~nm}$. The profiles of the aggregates show particles with heights between 60 and $150 \mathrm{~nm}$ and widths between $500 \mathrm{~nm}$ and $2 \mu \mathrm{m}$ (Figure 4(c)). These aggregates could be correlated to the partially soluble and insoluble compounds previously described. Figure 4(b) shows nanoparticles with heights of $20-30 \mathrm{~nm}$ and an average of $560 \pm 130 \mathrm{~nm}$ diameter, confirming the effectiveness of sonication and filtration processes in order to decrease the aggregate size and to form micellar-like structures, Figure 4(d). However, according to the DLS size distribution analysis, the sample is polydisperse (Figure 4(e)). Figure 4(f) shows aggregates of particles that tend to form on the mica surface, and these results suggest that aggregates could form in the solution and an extra cosurfactant could be added to stabilize the nanosuspension.

3.1. Nanoparticle Cytotoxicity and Irritability Tests. Significance difference in viability between the samples and the control was determined by an analysis of variance (ANOVA) test, followed by a Tukey post hoc test. No significant differences at $p<0.05$ between the control of viability (100\% growth) and the TEC-NP solutions were found. All aqueous solutions of nanoparticles are not cytotoxic to the 3T3 cell line used, achieving an increase higher than the control (100\%), as shown in Figure 5. The maximum value is 


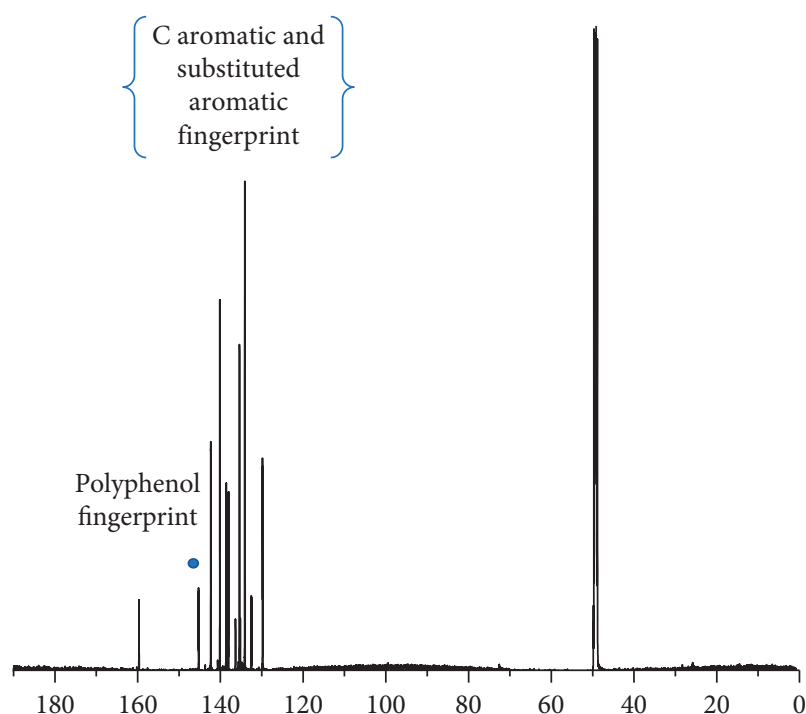

(a)

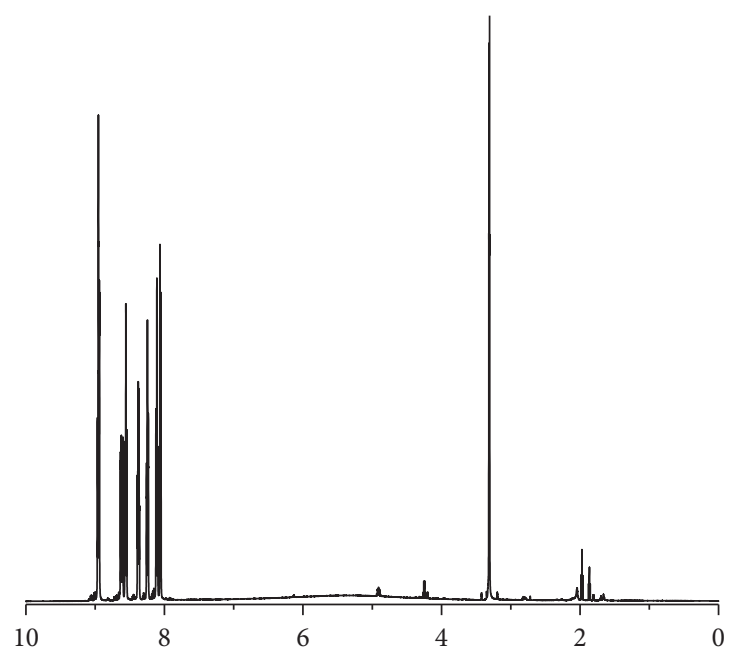

(b)

Figure 3: (a) ${ }^{13} \mathrm{C}-\mathrm{NMR}$ and (b) ${ }^{1} \mathrm{H}-\mathrm{NMR}$ of the TEC-NP suspension dried and redissolved in $\mathrm{CDCl}_{3}$.

TABle 6: Phenol quantification by the Folin-Ciocalteu method for Tinospora cordifolia ethanolic extract and nanoparticles.

\begin{tabular}{lcr}
\hline Sample & & Concentration $(\mathrm{mg} / \mathrm{mL})$ \\
& Mean & Standard deviation \\
\hline Alcoholic extract & 0.94 & 0.02 \\
Nanoparticles & 0.09 & 0.01 \\
\hline
\end{tabular}

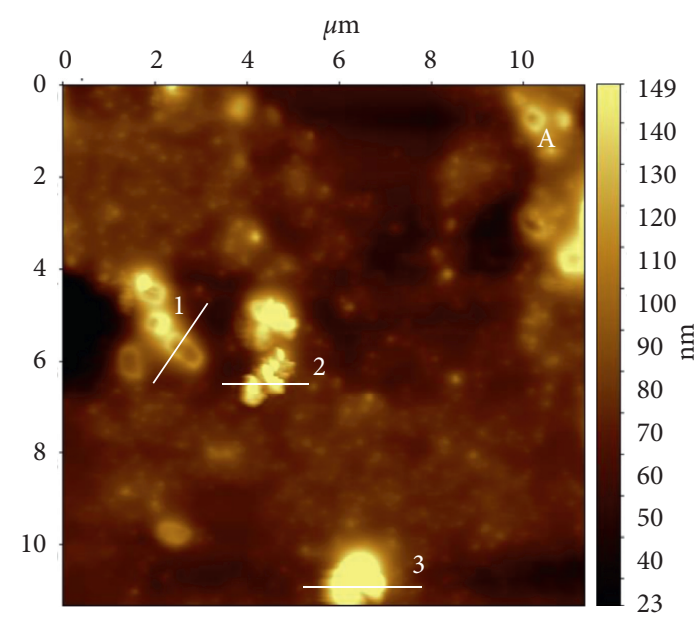

(a)

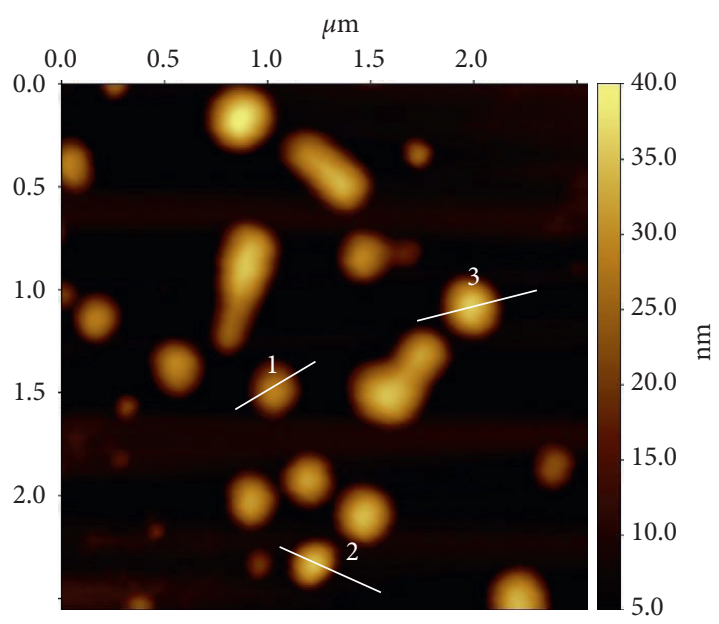

(b)

FIgURE 4: Continued. 


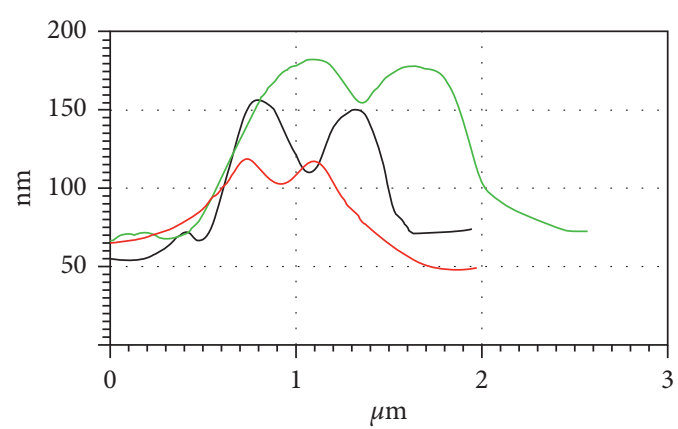

(c)

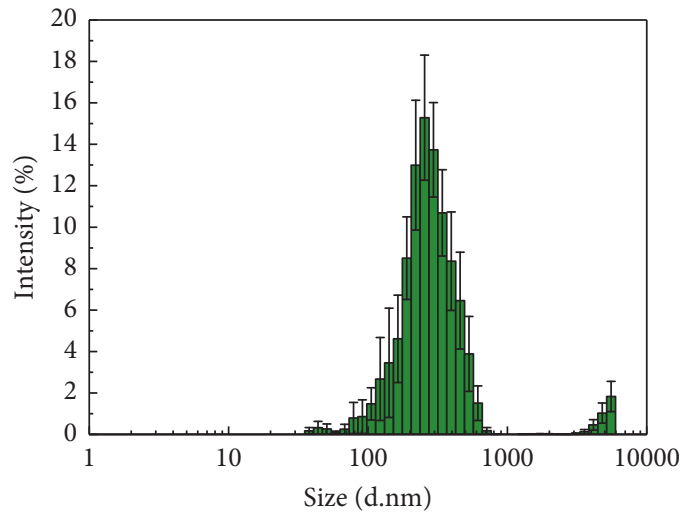

(e)

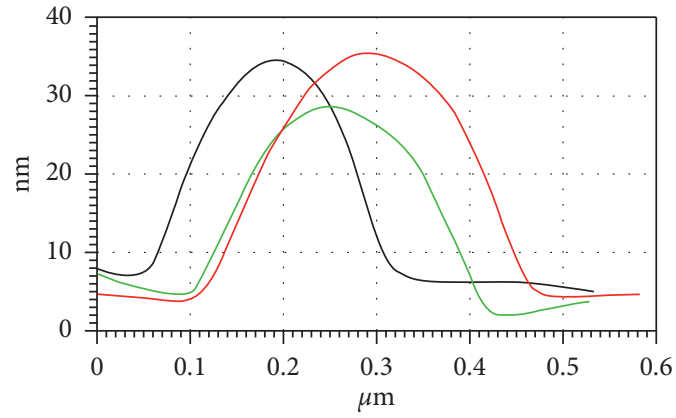

(d)

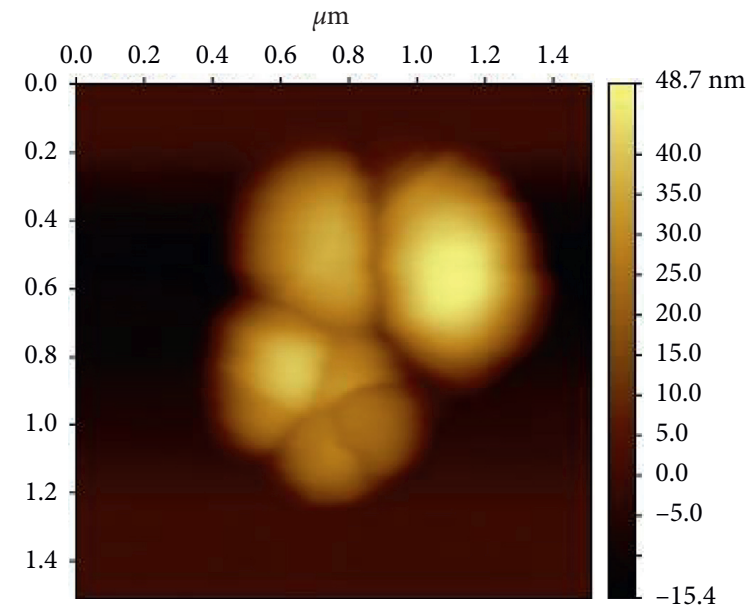

(f)

FIgURE 4: AFM topography image of (a) alcoholic TEC extract, (b) TEC NPs, (c, d) profile cross section (P) of lines shown in (a) and (b), respectively, (e) DLS size distribution, and (f) AFM topography image of NP aggregate.

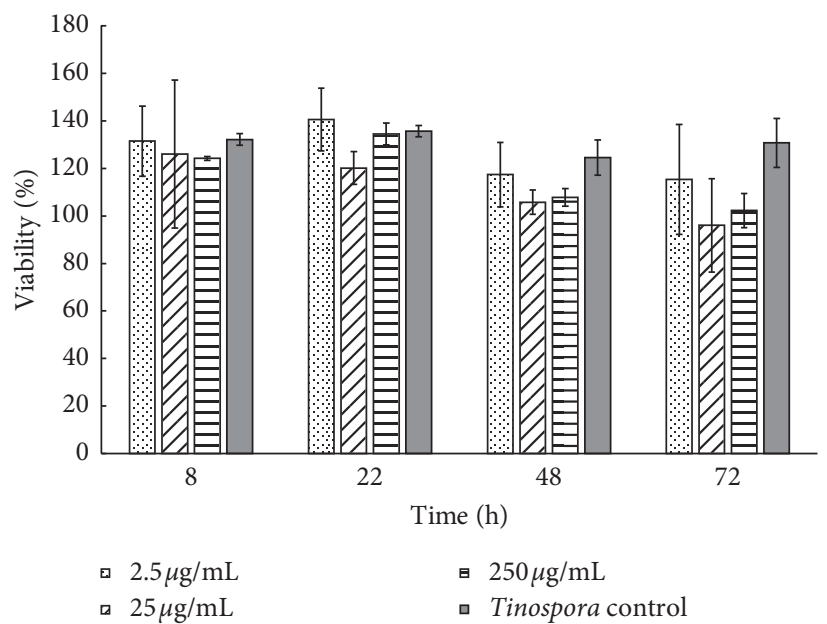

FIGURE 5: Cellular viability of 3T3 cell line incubated at different times of TEC-NPs in three concentrations (mean $\% \pm$ SD).

obtained from the aqueous solution of nanoparticles with a concentration of $2.5 \mu \mathrm{g} / \mathrm{mL}$, after 22 hours, whose viability is slightly higher than $140 \%$.

As observed in the summary of Tables 7 and 8, there were no severe alterations that compromised animal health and welfare. There was also no obvious irritation of the test substance in contact with the skin. Therefore, the TEC-NP in the concentration $12.45 \mathrm{mg} / \mathrm{mL}$ is classified as nonirritating, since no evident irritation was observed during the entire period of the test. These results are consistent with the research of other authors, without obtaining adverse results $[4,29]$. 
TABLe 7: Evaluation scale of dermal reactions (erythema and edema).

\begin{tabular}{|c|c|c|c|c|c|c|c|c|c|c|c|c|c|c|c|c|c|c|c|c|c|}
\hline \multirow{2}{*}{$\frac{\text { Erythema }}{\text { Animal }}$} & \multicolumn{3}{|c|}{ Day 1} & \multicolumn{3}{|c|}{ Day 2} & \multicolumn{3}{|c|}{ Day 3} & \multicolumn{3}{|c|}{ Day 4} & \multicolumn{3}{|c|}{ Day 5} & \multicolumn{3}{|c|}{ Day 6} & \multicolumn{3}{|c|}{ Day 7} \\
\hline & 1 & 2 & 3 & 1 & 2 & 3 & 1 & 2 & 3 & 1 & 2 & 3 & 1 & 2 & 3 & 1 & 2 & 3 & 1 & 2 & 3 \\
\hline Hair appearance & 0 & 0 & 0 & 0 & 0 & 0 & 0 & 0 & 0 & 0 & 0 & 0 & 0 & 0 & 0 & J & 0 & 0 & 0 & 0 & 0 \\
\hline Skin appearance & 0 & 0 & 0 & 0 & 0 & 0 & 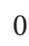 & 0 & 0 & 0 & 0 & 0 & 0 & 0 & 0 & 0 & 0 & 0 & 0 & 0 & 0 \\
\hline Eyes and mucous membranes & 0 & 0 & 0 & 0 & 0 & 0 & ( & 0 & 0 & 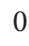 & 0 & 0 & 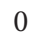 & 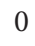 & ( & 0 & 0 & 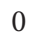 & ) & 0 & 0 \\
\hline Ataxia & 0 & 0 & 0 & 0 & 0 & 0 & & 0 & 0 & & 0 & 0 & U & 0 & 0 & J & 0 & 0 & U & 0 & 0 \\
\hline Paralysis & 0 & 0 & 0 & 0 & 0 & 0 & 0 & 0 & 0 & & 0 & 0 & 0 & 0 & 0 & 0 & 0 & 0 & 0 & 0 & 0 \\
\hline Reaction to stimuli & 0 & 0 & 0 & 0 & 0 & 0 & ( & 0 & 0 & C & 0 & 0 & 0 & 0 & 0 & 0 & 0 & 0 & 0 & 0 & 0 \\
\hline Peripheral vasoconstriction & 0 & 0 & 0 & & 0 & 0 & & 0 & 0 & & 0 & 0 & & 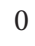 & 0 & & b & ( & & 0 & 0 \\
\hline Peripheral vasodilation & 0 & 0 & 0 & 0 & 0 & 0 & 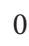 & 0 & 0 & & 0 & 0 & 0 & 0 & 0 & J & 0 & 0 & 0 & 0 & 0 \\
\hline Piloerection & 0 & 0 & 0 & 0 & 0 & 0 & 0 & 0 & 0 & 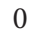 & 0 & 0 & 0 & 0 & 0 & 0 & 0 & 0 & 0 & 0 & 0 \\
\hline Salivation & 0 & 0 & 0 & 0 & 0 & 0 & & 0 & 0 & & 0 & 0 & & 0 & 0 & 0 & 0 & 0 & 0 & 0 & 0 \\
\hline Motor activity & 0 & 0 & 0 & & 0 & 0 & & 0 & 0 & & 0 & 0 & & 0 & 0 & & 0 & 0 & 0 & 0 & 0 \\
\hline Tremors and convulsions & 0 & 0 & 0 & & 0 & 0 & & 0 & 0 & & 0 & 0 & & 0 & 0 & & 0 & 0 & 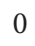 & 0 & 0 \\
\hline Breathing & 0 & 0 & 0 & 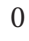 & 0 & 0 & 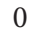 & 0 & 0 & 0 & 0 & 0 & 0 & 0 & 0 & 0 & 0 & 0 & 0 & 0 & 0 \\
\hline Dehydration & 0 & 0 & 0 & 0 & 0 & 0 & 0 & 0 & 0 & 0 & 0 & 0 & 0 & 0 & 0 & 0 & 0 & 0 & 0 & 0 & 0 \\
\hline Diarrhea & 0 & 0 & 0 & $\sigma$ & 0 & 0 & $\sqrt{0}$ & 0 & 0 & 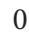 & 0 & 0 & 0 & 0 & 0 & 0 & 0 & 0 & 0 & 0 & 0 \\
\hline
\end{tabular}

TABLE 8: Evaluation scale of dermal reactions of edema.

\begin{tabular}{|c|c|c|c|c|c|c|c|c|c|c|c|c|c|c|c|c|c|c|c|c|c|}
\hline \multirow{2}{*}{$\frac{\text { Edema }}{\text { Animal }}$} & \multicolumn{3}{|c|}{ Day 8} & \multicolumn{3}{|c|}{ Day 9} & \multicolumn{3}{|c|}{ Day 10} & \multicolumn{3}{|c|}{ Day 11} & \multicolumn{3}{|c|}{ Day 12} & \multicolumn{3}{|c|}{ Day 13} & \multicolumn{3}{|c|}{ Day 14} \\
\hline & 1 & 2 & 3 & 1 & 2 & 3 & 1 & 2 & 3 & 1 & 2 & 3 & 1 & 2 & 3 & 1 & 2 & 3 & 1 & 2 & 3 \\
\hline Hair appearance & 0 & 0 & 0 & 0 & 0 & 0 & 0 & 0 & 0 & 0 & 0 & 0 & 0 & 0 & 0 & 0 & 0 & 0 & 0 & 0 & 0 \\
\hline Skin appearance & 0 & 0 & 0 & 0 & 0 & 0 & 0 & 0 & 0 & 0 & 0 & 0 & 0 & 0 & 0 & 0 & 0 & 0 & 0 & 0 & 0 \\
\hline Eyes and mucous membranes & 0 & 0 & 0 & 0 & 0 & 0 & 0 & 0 & 0 & 0 & 0 & 0 & 0 & 0 & 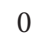 & 0 & ) & & 0 & 0 & 0 \\
\hline Ataxia & 0 & 0 & 0 & 0 & 0 & 0 & 0 & 0 & 0 & 0 & 0 & 0 & 0 & 0 & 0 & 0 & 0 & 0 & 0 & 0 & 0 \\
\hline Paralysis & 0 & 0 & 0 & 0 & 0 & 0 & 0 & 0 & 0 & 0 & 0 & 0 & 0 & 0 & 0 & 0 & 0 & 0 & 0 & 0 & 0 \\
\hline Reaction to stimuli & 0 & 0 & 0 & 0 & 0 & 0 & 0 & 0 & 0 & 0 & 0 & 0 & 0 & 0 & 0 & 0 & 0 & 0 & 0 & 0 & 0 \\
\hline Peripheral vasoconstriction & 0 & 0 & 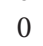 & 0 & 0 & 0 & 0 & 0 & 0 & 0 & 0 & 0 & 0 & 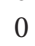 & 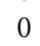 & 0 & 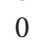 & 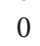 & 0 & 0 & 0 \\
\hline Peripheral vasodilation & 0 & 0 & 0 & 0 & 0 & 0 & 0 & 0 & 0 & 0 & 0 & 0 & 0 & 0 & 0 & 0 & 0 & 0 & 0 & 0 & 0 \\
\hline Piloerection & 0 & 0 & 0 & 0 & 0 & 0 & 0 & 0 & 0 & 0 & 0 & 0 & 0 & 0 & 0 & 0 & 0 & 0 & 0 & 0 & 0 \\
\hline Salivation & 0 & 0 & 0 & 0 & 0 & 0 & 0 & 0 & 0 & 0 & 0 & 0 & 0 & 0 & 0 & 0 & 0 & 0 & 0 & 0 & 0 \\
\hline Motor activity & 0 & 0 & 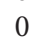 & 0 & 0 & 0 & 0 & 0 & 0 & 0 & 0 & 0 & 0 & 0 & 0 & 0 & 0 & 0 & 0 & 0 & 0 \\
\hline Tremors and convulsions & 0 & 0 & 0 & 0 & 0 & 0 & 0 & 0 & 0 & 0 & 0 & . & 0 & . & 0 & 0 & 0 & 0 & 0 & 0 & 0 \\
\hline Breathing & 0 & 0 & 0 & 0 & 0 & 0 & 0 & 0 & 0 & 0 & 0 & 0 & 0 & 0 & 0 & 0 & 0 & 0 & 0 & 0 & 0 \\
\hline Dehydration & 0 & 0 & 0 & 0 & 0 & 0 & 0 & 0 & 0 & 0 & 0 & 0 & 0 & 0 & 0 & 0 & 0 & 0 & 0 & 0 & 0 \\
\hline Diarrhea & 0 & 0 & 0 & 0 & 0 & 0 & 0 & 0 & 0 & 0 & 0 & 0 & 0 & 0 & 0 & 0 & 0 & 0 & 0 & 0 & 0 \\
\hline
\end{tabular}

\section{Conclusions}

Stable Tinospora cordifolia stem derivate nanoparticles, with a hydrodynamic diameter of $182.9 \pm 3.8 \mathrm{~nm}$, were obtained in water by sonication. Polyphenols, alkaloids, and tinocordiside compose the nanoparticles. The nanoparticle cellular viability tests showed that they do not decrease the $3 \mathrm{~T} 3$ fibroblast viability at a concentration range of $2.5-250 \mu \mathrm{g} / \mathrm{mL}$ and that are cytocompatible. In addition, its effect in dermal irritability showed no skin irritation of the New Zealand rabbit at $12.45 \mathrm{mg} / \mathrm{mL}$. In vivo tests could confirm the viability in humans and a potential application in biomedicine, antiageing formulations, or others.

\section{Data Availability}

The results used to support the findings of this study are available from the corresponding author upon request (drpazsowarigpa@gmail.com).

\section{Conflicts of Interest}

The authors declare that they have no conflicts of interest.

\section{References}

[1] R. Mishra and G. Kaur, "Tinospora cordifolia induces differentiation and senescence pathways in neuroblastoma cells," Molecular Neurobiology, vol. 52, no. 1, 2014.

[2] U. Spandana, S. Liakhat, T. Nirmala, M. Santhi, and S. Sipai, "A review on tinospora cordifolia," International Journal of Current Pharmaceutical Review and Research, vol. 4, no. 2, pp. 61-68, 2013.

[3] G. Abiramasundari and M. Sreepriya, "Pro-stimulatory effects of tinospora cordifolia (menispermaceae) on SAOS-2 osteoblast cells implications on bona remodeling and therapy of osteoporosis," Journal of Pharmaceutical, Biological and Chemical Sciences, vol. 5, no. 3, pp. 354-363, 2014.

[4] M. Imtiyaj, S. G. P. Harsha, and G. Ravishankar, "Pigment identification, antioxidant activity, and nutrient composition of Tinospora cordifolia (willd.) Miers ex Hook. f \& Thoms 
fruit," International Journal of Food Sciences and Nutrition, vol. 62, no. 3, pp. 239-249, 2011.

[5] I. Aranha, F. Clemente, and Y. Venkatesh, "Immunostimulatory properties of the major protein from the stem of the ayurvedic medicinal herb, guduchi (Tinispora cordifolia)," Journal of Ethonopharmacology, vol. 139, pp. 366-372, 2011.

[6] S. Jain, B. Sherlekar, and R. Barik, "Evaluation of antioxidant potntial of Tinospora cordifolia and tinospora sinensis," International Journal of Pharmaceutical Sciences and Research, vol. 1, no. 11, pp. 122-128, 2010.

[7] T. Khan, A. Ipshita, R. Mazumdar, A. Abdullah, G. Islam, and M. Rahman, "Bioactive polyphenol profiling and in-vitro antioxidant activity of Tinospora cordifolia Miers ex Hook F and Thoms: a potential ingredient for functional food development," Bangladesh Journal of Scientific and Industrial Research, vol. 55, no. 1, pp. 23-34, 2020.

[8] S. Saha and S. Ghosh, "Tinospora cordifolia: one plant, many roles," Ancient Science of Life, vol. 31, no. 4, pp. 151-159, 2012.

[9] M. Pandey, S. Chikara, M. S. R. Vyas, and G. B. P. Thakur, "Tinospora cordifolia: a climbing shrub in health care management," International Journal of Pharma and Bio Sciences, vol. 3, no. 4, pp. 612-628, 2012.

[10] P. Ruthiran, L. Ravi, and I. Selvaraj, "Phytochemical screening, FT-IR and gas chromatography mass spectrometry analysis of Tinospora cordifolia (Thunb.) Miers," International Journal of Pharmacognosy and Phytochemical Research, vol. 8, no. 12, pp. 2020-2024, 2016.

[11] H. E. Gottlieb, V. Kotlyar, and A. Nudelman, "NMR chemical shifts of common laboratory solvents as trace impurities," The Journal of Organic Chemistry, vol. 62, no. 21, pp. 7512-7515, 1997.

[12] R. K. Harris, E. D. Becker, S. M. Cabral de Menezes, P. Granger, and R. E. Hoffman, "Further conventions for NMR shielding and chemical shifts (IUPAC Recommendations 2008)," Pure and Applied Chemistry, vol. 80, no. 1, pp. 59-84, 2008.

[13] U. Sharma, M. Bala, N. Kumar, B. Singh, R. K. Munshi, and S. Bhalerao, "Immunomodulatory active compounds from Tinospora cordifolia," Journal of Ethnopharmacology, vol. 141, no. 3, pp. 918-926, 2012.

[14] M. Padma, B. Govindh, and B. Venkateswara, "Synthesis \& characterization of fluorescent silver nanoparticles stabilized by Tinospora Cordifolia leaf extract a green procedure," Journal of Engineering Research and Applications, vol. 4, no. 9, pp. 100-107, 2014.

[15] T. Abbasi, J. Anuradha, and S. Abbasi, "Utilization of the terrestrial weed Guduchi (Tinospora cordifolia) in cleangreen synthesis of gold nanoparticles," Nanoscience \& Technology, vol. 1, no. 3, pp. 1-7, 2014.

[16] N. Uddin, N. Akter, M. Sagar, and M. Habibur, "New stigmasterol and long chain alcohol from Tinospora cordifolia," International Journal of Multidisciplinary Research and Development, vol. 2, no. 8, pp. 143-145, 2015.

[17] H. Espinosa and Y. E. García, Tecnologías de nano/ microencapsulación, Jalisco: CIATEJ, Zapopan, Mexico, 2017.

[18] S. Sultana, M. Ali, and M. Jameel, "Phytochemical investigation and isolation of new compounds from the stems of Tinospora cordifolia Miers," Trends in Phytochemical Research (TPR), vol. 1, no. 2, pp. 83-92, 2017.

[19] A. Sinha, H. Sharma, B. Singh, and A. Patnaik, "Phytochemical studies of methanol extracts of tinospora cordifolia stem by GC-MS," World Journal of Pharmaceutical Research, vol. 6, no. 4, pp. 1319-1326, 2017.

[20] H. Fulcrand, C. Mané, S. Preys et al., "Direct mass spectrometry approaches to characterize polyphenol composition of complex samples," Phytochemistry, vol. 69, no. 18, pp. 3131-3138, 2008.

[21] S. Ghosal and R. A. Vishwakarma, "Tinocordiside, a new rearranged cadinane sesquiterpene glycoside from Tinospora cordifolia," Journal of Natural Products, vol. 60, no. 8, pp. 839-841, 1997.

[22] National Center for Biotechnology Information, PubChem Database, 9 Agosto, National Center for Biotechnology Information, Bethesda, MA, USA, 2009.

[23] K. Antul, P. Amandeep, S. Gurwinder, and C. Anuj, "Review on pharmacological profile of medicinal vine: Tinospora cordifolia," Current Journal of Applied Science and Technology, vol. 35 , no. 5 , pp. 1-11, 2019.

[24] D. Singh and P. K. Chaudhuri, "Chemistry and pharmacology of Tinospora cordifolia," Natural Product Communications, vol. 12, no. 2, pp. 299-308, 2016.

[25] J. Chakraborty, M. S. Hafez Kabir, H. Banik et al., "In silico pass prediction, molecular docking and ADME/T property analysis of isolated compounds form Tinospora cordifolia for new thrombolytic drug discovery," World Journal of Pharmaceutical Research, vol. 5, no. 7, pp. 1751-1760, 2016.

[26] M. Balaa, P. Kumar Verma, S. Awasthi, N. Kumar, B. Lal, and B. Singh, "Chemical prospection of important ayurvedic plant Tinospora cordifolia by UPLC-DAD-ESI-QTOF-MS/MS and NMR," Natural Product Communications, vol. 10, no. 1, pp. 43-48, 2015.

[27] M. A. M. Nawwar, S. A. M. Hussein, and I. Merfort, "NMR spectral analysis of polyphenols from punica granatum," Phytochemistry, vol. 36, no. 3, pp. 793-798, 1994.

[28] W. Li, K. Weu, H. Fu, and K. Koike, "Structure and absolute configuration of clerodane diterpene glycosides and a rearranged cadinane sesquiterpene glycoside from the stems of Tinospora sinensis," Journal of Natural Products, vol. 70, no. 12, pp. 1971-1976, 2007.

[29] M. Girish and K. Priyadarshini, "Influence of Tinospora cordifolia on wound healing in albino rats," International Journal of Pharma \& Bio Sciences, vol. 3, no. 2, pp. 379-384, 2012. 